\title{
A mathematical model as a tool to identify microRNAs with highest impact on transcriptome changes
}

\author{
Marzena Mura ${ }^{1,2^{*}}$ D , Roman Jaksik ${ }^{1,3}$, Anna Lalik ${ }^{1,3}$, Krzysztof Biernacki ${ }^{5}$, Marek Kimmel ${ }^{1,4}$, \\ Joanna Rzeszowska-Wolny ${ }^{1,3^{*}}$ and Krzysztof Fujarewicz ${ }^{1}$
}

\begin{abstract}
Background: Rapid changes in the expression of many messenger RNA (mRNA) species follow exposure of cells to ionizing radiation. One of the hypothetical mechanisms of this response may include microRNA (miRNA) regulation, since the amounts of miRNAs in cells also vary upon irradiation. To address this possibility, we designed experiments using cancer-derived cell lines transfected with luciferase reporter gene containing sequences targeted by different miRNA species in its $3^{\prime}-$ untranslated region. We focus on the early time-course response (1 h past irradiation) to eliminate secondary mRNA expression waves.
\end{abstract}

Results: Experiments revealed that the irradiation-induced changes in the mRNA expression depend on the miRNAs which interact with mRNA. To identify the strongest interactions, we propose a mathematical model which predicts the mRNA fold expression changes, caused by perturbation of microRNA-mRNA interactions. Model was applied to experimental data including various cell lines, irradiation doses and observation times, both ours and literature-based. Comparison of modelled and experimental mRNA expression levels given miRNA level changes allows estimating how many and which miRNAs play a significant role in transcriptome response to stress conditions in different cell types. As an example, in the human melanoma cell line the comparison suggests that, globally, a major part of the irradiation-induced changes of mRNA expression can be explained by perturbed miRNA-mRNA interactions. A subset of about 30 out of a few hundred miRNAs expressed in these cells appears to account for the changes. These miRNAs play crucial roles in regulatory mechanisms observed after irradiation. In addition, these miRNAs have a higher average content of GC and a higher number of targeted transcripts, and many have been reported to play a role in the development of cancer.

Conclusions: Our proposed mathematical modeling approach may be used to identify miRNAs which participate in responses of cells to ionizing radiation, and other stress factors such as extremes of temperature, exposure to toxins, and drugs.

Keywords: miRNA, miRNA-mRNA interactions, ionizing radiation, stressing factor

\footnotetext{
*Correspondence: marzena.mura@polsl.pl; joanna.rzeszowska@pols.pl

'Department of Systems Engineering, Institute of Automatic Control, Silesian

University of Technology, ul. Akademicka 16, 44-100 Gliwice, Poland

Full list of author information is available at the end of the article
}

(c) The Author(s). 2019 Open Access This article is distributed under the terms of the Creative Commons Attribution 4.0 International License (http://creativecommons.org/licenses/by/4.0/), which permits unrestricted use, distribution, and reproduction in any medium, provided you give appropriate credit to the original author(s) and the source, provide a link to the Creative Commons license, and indicate if changes were made. The Creative Commons Public Domain Dedication waiver (http://creativecommons.org/publicdomain/zero/1.0/) applies to the data made available in this article, unless otherwise stated. 


\section{Background}

Response of human cells to electromagnetic radiation is of paramount importance in many contexts, including the intertwined fields of carcinogenesis and radiation therapy of cancer. Obtaining insights into the qualitative and quantitative nature of the response is complicated by superposition of potential mechanisms of primary and secondary response. For this reason, we focus on the short-term transcriptional response (mostly up to $1 \mathrm{~h}$ past irradiation), and in particular its regulation by other RNA species. Because of this relatively narrow focus, it seems possible to propose that a simple, non-mechanistic, statistical model helps to identify and quantitate the leading components of this regulation and that the modelling outcomes are free of statistical bias.

Rapid changes in the expression of many messenger RNAs (mRNAs) follow exposure of cells to irradiation by $\mathrm{X}$-rays, and the change of expression of up- or down-regulated mRNAs is strongly correlated with the distribution of microRNA (miRNA) recognition motifs in their non-coding 3'-UTR sequence [1]. One of the factors regulating the expression of mRNAs is degradation of transcripts mediated by miRNAs, small noncoding RNAs strongly conserved throughout evolution which, together with the proteins from the Argonaute family, function as RNA-induced silencing complexes (RISCs) [2-4]. Complementarity of a 6-8 nucleotide-long region at the $5^{\prime}$ end of a miRNA (the "seed" region) to a target sequence in a primary transcript is necessary for mRNA-RISC interaction and leads to faster or slower mRNA degradation [5]. A single miRNA may regulate many mRNAs and a single transcript may contain sequence motifs targeted by different miRNAs [5]. The miRNA-directed regulation plays an important role in establishing the expressions of mRNAs and their translation rates and is involved in cell proliferation, differentiation, apoptosis, stress responses, immune responses, and diseases including cancer [6-10]. It is therefore important to understand the molecular mechanisms by which miRNAs regulate mRNA levels and how the regulation is affected by stress factors.

The motivation for research described in this paper was provided by preliminary experimental studies, in which we examined the influence of motifs in the 3' UTR of a luciferase reporter gene (see Methods), recognized by members of let-7 family, miR-21, and miR-24, on ionizing radiation-induced changes in the luciferase mRNA expression. We were mostly interested in early-phase response, before any later effects of irradiation might interfere. Therefore, we focused on the change in luciferase expression between the $0 \mathrm{~h}$ (immediately before irradiation), and the $1 \mathrm{~h}$ time points. A statistically significant increase ( $p$-value $<0.05)$ of expression of luciferase mRNA occurred after irradiation when the primary transcript contained motifs targeted by miR-21 or miR-24, but in contrast no significant increase occurred in transcripts targeted by let-7 or devoid of miRNA-targeted motifs (Fig. 1). This suggested that mRNA response to irradiation depended on its interactions with specific miRNAs.

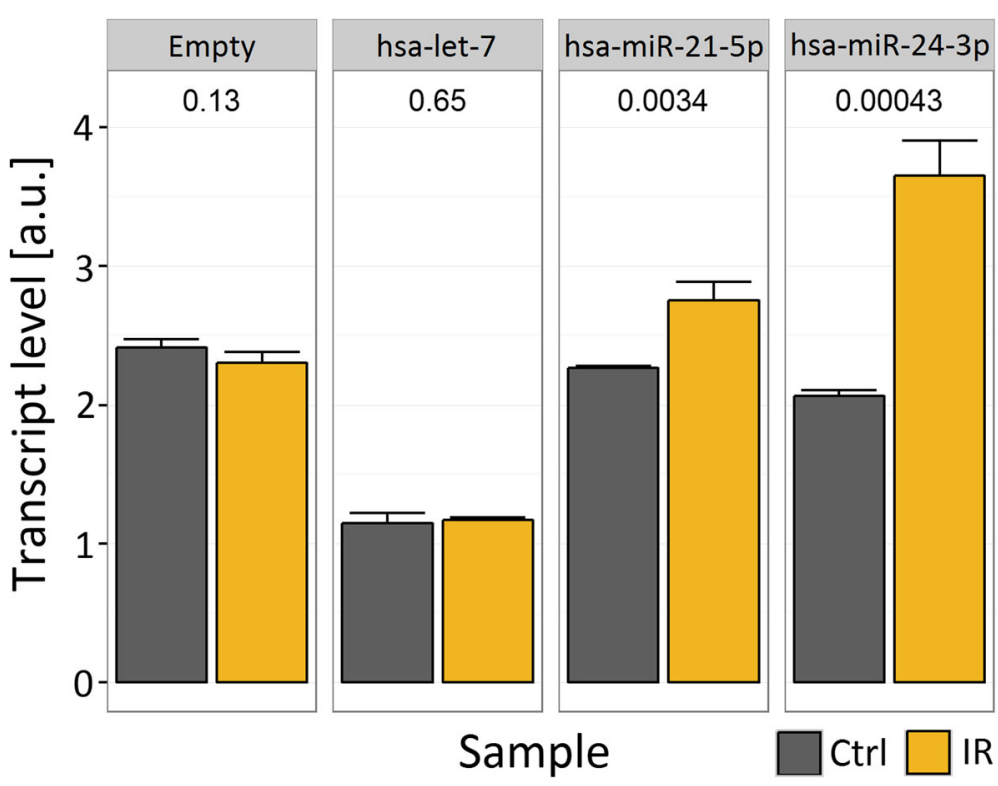

Fig. 1 Levels of Renilla luciferase mRNA in control and irradiated Me45 cells. Cells were transfected with a reporter gene plasmid containing a Renilla luciferase gene with the same promoter and coding sequence but whose primary transcript contained target sequences for different miRNAs versus those that did not contain the targets (empty). Renilla mRNA was assayed by RT-PCR and normalized to the Firefly mRNA to exclude differences in transfection efficiency between experiments. Error bars represent standard deviations of values obtained in three experiments, and $p$-values show the significance of differences between control and irradiated samples tested by a two sample t-test 
However, to understand the process in quantitative detail and build a mathematical model, we decided to employ microarrays, which deliver data on multiple mRNAs and miRNA.

The processes of regulation of gene expression by miRNAs are subject of a number of studies using systems biology approaches $[11,12]$. They were also modelled using approaches ranging from a single mechanism $[13,14]$ to multiple mechanisms influenced by miRNA action [15]. Modelling of these processes is based on data from miRNA and mRNA microarrays [16-23] or RNA sequencing [24], which allow tracking changes in the level of multiple miRNAs and mRNA. Large-scale studies have been based on measurement of correlations $[16,19,20]$, linear regression $[17,25]$, partial least square regression with bootstrap-based statistical tests [18], least angle regression [23], chemical kinetics eqs. [21], or Bayesian methods [26]. Methods to find relevant regulatory associations are based on expression data for miRNAs and mRNAs and publicly-available miRNA target prediction algorithms such as MAGIA [27] and MIMA [28]. The method presented in this paper is based on dynamic changes of mRNA expression, as opposed to previous studies that mostly considered single time point measurements (see the summary of the most popular methods in ref. [29]).

In this paper we propose a simple mathematical model constructed based on microarray data. The purpose of the model is to predict changes of mRNA levels in cells exposed to ionizing radiation which may contribute to identifying the miRNAs and mRNAs involved. The hypothesis tested by the model is based on our previous studies of the changes of mRNA and miRNA levels in cells after exposure to X-radiation [1, 30], which suggests that in many cases changes in mRNA expressions result from radiation-induced perturbation of the interactions of miRNAs with mRNAs. We propose that the influence of cognate miRNAs on the change of level of single mRNA depends on the number of miRNA binding sites in the 3 '-untranslated region (UTR). The mechanism of perturbations in miRNA-mRNA interactions is not specifically included in the model, which therefore might be classified as statistical. Speculatively, the mechanism may be the consequence of RNA or RISC proteins damage by radiation or changes in miRNA biogenesis and concentration. Changes of mRNA levels computed from the model show good correlation with experimental microarray data for irradiated cells. This suggests that in some cell types major part of these changes can be assigned to perturbed mRNA-miRNA interactions and that only a small subset of miRNAs (7\% of miRNAs expressed in melanoma Me45 cells) participates in this effect.

\section{Methods}

\section{Cell culture and irradiation}

Human melanoma Me45 cell line (established in the Center of Oncology in Gliwice), K562 cell line, and two HCT116 cell lines with different P53 status (ACCT collection) were grown in DMEM/F12 medium in RPMI 1640, both with L-glutamine (Sigma-Aldrich), 10\% fetal bovine serum (Gibco), and $80 \mu \mathrm{g} / \mathrm{ml}$ gentamycin at $37^{\circ} \mathrm{C}$ in a humidified atmosphere and $5 \% \mathrm{CO}_{2}$. Exponentially growing cells were irradiated at room temperature with 4 Gy $(1 \mathrm{~Gy} / \mathrm{min})$ of $6 \mathrm{MV}$ X-ray photons generated by a therapeutic accelerator (Clinac 600) in fresh culture medium (changed 15 min before irradiation).

\section{Transfection with reporter genes}

Me45 cells were transfected with psiCHECK2 plasmid (Promega) containing two luciferase genes, Firefly luciferase being a reference and Renilla luciferase with eight tandem repeats of various miRNA target sites in its 3'UTR being the reporter gene. The plasmid contained sequences targeted by either the miRNA let-7, miR-21 or miR-24. The let-7 target sequence had motif TCGAGACTA TACAAGGATCTACCTCAG, $71.75 \%$ average complementarity to the target sequences of various mature let- 7 family members [31]. The miR-21 target sequence had motif TCAACATCAGTCTGATAAGCTAAA, 100\% complementarity to the mature miR-21 target; the two last AA form a spacer to limit complementarity for nonspecific binding. The miR-24 target sequence had motif ATAC GACTGGTGAACTGAGCCG, $68 \%$ complementarity to the mature miR-24 target. Sequence synthesis, insertion, and verification were performed by the BLIRT S.A. company (Gdansk, Poland). The unmodified plasmid was used as a control (empty). Transfection was performed with lipofectamine (Invitrogen) according to the supplier's protocol. Transfected cells were irradiated in the same conditions as non-transfected cells.

\section{Measurement of mRNA and miRNA levels}

Microarray data for normal cell lines: AG1522, PBMC, HCAEC, and cancer cell lines: DU145, SC3, MOLT4 analyzed in this paper were downloaded from ArrayExpress database [32]. Additional file 1: Table S1 includes ID numbers of individual experiments.

mRNA and miRNA levels were estimated by Affymetrix (Human Genome U133A) and Agilent (G4870A SurePrint G3 Human v16 miRNA 8x60k) microarrays 1, 12 and $24 \mathrm{~h}$ after irradiating the cells, with control being the non-irradiated cells at $1 \mathrm{~h}$, as described in [30]; these data are available in the ArrayExpress database (accession numbers E-MEXP-2623, and E-MTAB-5197 for mRNAs and miRNAs, respectively). The mRNA and miRNA datasets for Me45, $\mathrm{K} 562$ and $\mathrm{HCT}_{11} 6^{+/+}$cell lines were already explored. In the previous publications 
authors focused on the relation between reactive oxygen species and miRNA [1] and bystander effects [30, 33]. HCT $116^{-/-}$expression levels were not published previously. All datasets were normalized by the standard RMA method [34]. Only mRNAs and miRNAs with expression above the noise level were selected for analysis using the GaMRed software, which uses Gaussian mixture models [35]. The default parameter values were applied, i.e., number of initial conditions 100, number of components 2 to 8, Expectation-Maximization (EM) algorithm precision level $10^{-2}$, and maximum number of EM interactions 5000. Two methods were used for choosing the number of components to remove, the "top three" rule which finds groups of genes with high, medium or low expression and removes others, or the " $k$-means" method which uses $k$-means clustering and statistical information to remove clusters of non-informative genes [35]. Both methods returned the same noise level threshold. The noise level threshold does not have a significant impact on the prediction method; a detailed analysis is presented in Supplementary Material (Additional file 2: Figure S1). The numbers of mRNAs and miRNAs considered in individual cell lines are presented in Additional file 3: Table S2.

\section{Identifying miRNA-targeted motifs in primary transcripts} miRNA directly binds to a subset of mRNAs in binding site regions. The numbers of these sites are model parameters (see further on). Several tools for miRNA target prediction have been developed using different approaches [36]; we used information from four different algorithms. The number of miRNA binding sites was estimated using:miRanda3.3a [37], TargetScan [38], RNAhybrid [39], and NucleoSeq [40]. As different algorithms may return different results, the influence of a particular $i$-th miRNA on the $j$-th mRNA was expressed as the weighted sum of all four algorithms:

$$
c^{\prime}{ }_{j i}=\sum_{k=1}^{a} c_{j i}^{k} w_{k}
$$

where $a$ is the number of algorithms used ( $a=4$ here), $c_{j i}^{k}$ is the number of binding sites for the $i$-th miRNA in the 3'UTR of the $j$-th mRNA predicted by the $k$-th algorithm, and $w_{k}$ is the weight assigned to the $k$-th algorithm. The weight coefficient values for each method were allocated in proportion to the number of the features considered by a given algorithm. Table 1 presents prediction features used by the 4 algorithms [36].

Additional settings used in prediction algorithms include: strict option of the miRanda which requires strict alignment with the seed region and $p$-value of $<0.05$ and a free energy $\leq-30$ for predicted miRNA-mRNA hybrid binding sites.

\section{Identification of sequence motifs which potentially influence mRNA levels}

Additional information, not included directly in the model but useful for interpretation of results, concerned mRNA properties. Adenylate-uridylate-rich (ARE) motifs were identified using NucleoSeq [40] based on 3'-untranslated regions (UTRs) from the RefSeq transcript database and the TTATTTAWW consensus sequence [41]. Messenger RNA turnover times were derived from the experiments of Tani et al. on HeLa cells [42]. The association of transcription factor (TF) response elements with genes was based on a ChIP-Seq experiment performed by the ENCODE project [43]; a TF-gene association table was created using a map of TF-binding site positions in the genome available as a USCS track (wgEncodeRegTfbsClusteredV3). A TF was assumed to regulate a particular gene if its binding site was located between $5000 \mathrm{bp}$ upstream and $1000 \mathrm{bp}$ downstream of the transcription start site, taking into account the strand directionality of the gene.

\section{A model to predict changes of mRNA levels in irradiated cells}

We assumed that the change of expression of a mRNA in irradiated cells depends on the interacting miRNAs, and we considered that this principle could be applied generally to the expressions of mRNAs in a population of cells at cell cycle equilibrium. Interaction of a RISC complex with a transcript depends on the formation of a miRNA-mRNA hybrid, whose probability is determined predominantly by the number of miRNA-targeted motifs in the transcript and by the availability of the cognate targeting miRNAs. The impact of a particular ( $i$-th) miRNA on the level of a particular ( $j$-th) mRNA, shown schematically in Fig. 2a, is described by the expression:

$$
-k_{i} c_{j i}^{\prime} m i R N A_{i}
$$

Table 1 Algorithms for predicting miRNA target sequences

\begin{tabular}{llllll}
\hline Method & Text scan for miRNA motif & Binding energy & Sequence conservation & RNA folding & Weight coefficient \\
\hline miRanda3.3a & Yes & Yes & No & Yes & 0.3 \\
TargetScan & Yes & Yes & Yes & No & 0.3 \\
RNAhybrid & Yes & Yes & No & Yes & 0.3 \\
NucleoSeq & Yes & No & No & No & 0.1 \\
\hline
\end{tabular}




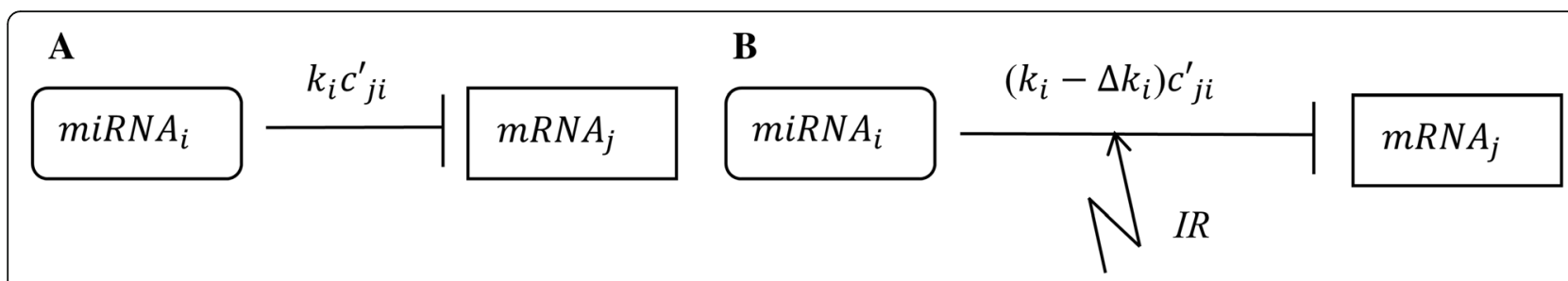

Fig. 2 Negative impact of the $i$-th miRNA on the expression level of the $j$-th mRNA (a) in normal conditions or (b) in irradiated cells

where $k^{i}$ is a proportionality factor (specific for the $i$-th miRNA and reflecting its activity), $m i R N A^{i}$ is the $\log ^{2}$ transformed expressions of the $i$-th miRNA, and $c^{j i}$ is coefficient reflecting the number of motifs recognized by a particular $(i$-th) miRNA on a particular $(j$-th) transcript (identification of the number of miRNA-targeted motifs $c^{j i}$ for specific cellular mRNAs is described in Methods). The minus sign in Eq. (1) denotes the negative impact of interaction with a transcript. Eq. (1) represents effect of miRNA inducible gene silencing in unperturbed cellular conditions

Our model proposes that in irradiated cells, the outcome (Equation (1)) is modified by decreasing the proportionality factor $k_{i}$ by $\Delta k_{i}$, depending on a change of the miRNA-mRNA interactions, as shown in Fig. $2 b$ and expressed mathematically by the formula:

$$
-\left(k_{i}-\Delta k_{i}\right) c \prime_{j i} m i R N A_{i}
$$

In other words, the effect of miRNA-inducible gene silencing can change after cell irradiation. Interpretation of the notation used in Equation (2):

- if $\Delta k_{i}>0$, then the negative regulation decreases so that expression of the $m R N A_{j}$ increases;

- if $\Delta k_{i}<0$. then the negative regulation increases so that expression of the $m R N A_{j}$ decreases.

Subtracting Equations (1) and (2) side-by-side, we obtain the change of the outcome resulting from irradiation:

$$
\Delta k_{i} c_{j i} m i R N A_{i}
$$

Most transcripts contain multiple recognition motifs for one or different miRNAs [44]. In a parsimonious form, the influence of irradiation for a particular mRNA can be estimated by the sum of the influences of different miRNAs:

$$
\sum_{i=1}^{N_{m i}} \Delta k_{i} c_{j i} m i R N A_{i}
$$

where $N_{m i}$ is the number of types of miRNA which recognize the transcript. The total effect of irradiation on the level of a $m R N A_{j}$, expressed as a binary logarithmic fold change (FC), can be described by the expression

$$
F C m R N A_{j}=\sum_{i=1}^{N_{m i}} \Delta k_{i} c_{j i} m i R N A_{i}+b_{0}
$$

which is a prediction of the experimentally observed fold change

$$
F C m R N A_{j}^{e x p}=m R N A_{j}^{I R}-m R N A_{j}^{0}
$$

where $m R N A_{j}^{0}$ and $m R N A_{j}^{I R}$ are the $\log _{2}$ transformed expressions of the $j$-th mRNA before and after irradiation. The additional constant $b_{0}$ equation (5) represents possible change of the expression of a mRNA which are independent of miRNAs and are similar for all mRNAs, for example breakage of a fraction of mRNA molecules by radiation. Usually $b_{0}$ has order of magnitude of $10^{-1}$.

The $c_{j i}$ elements for all mRNAs and all miRNAs form a matrix $C$ of size $N_{m} \times N_{m i}$, where $N_{m}$ is the number of different mRNAs and $N_{m i}$ is the number of different miRNAs. Each row of the matrix $C$ created for a particular gene sums the information on the impact of different miRNA-mRNA interactions on the expressions of one particular mRNA. This model can be written for all mRNAs as a matrix equation:

$$
F C m R N A=A \Delta k+b
$$

where:

$$
\begin{gathered}
A=C^{\prime} \operatorname{diag}(m i R N A) . \\
F C m R N A=\left[F C m R N A_{1}, F C m R N A_{2}, \ldots, F C m R N A_{N_{m i}}\right]^{T} \\
\Delta k=\left[\Delta k_{1}, \Delta k_{2}, \ldots, \Delta k_{N_{m i}}\right]^{T} \\
\operatorname{miRNA}=\left[m i R N A_{1}, m i R N A_{2}, \ldots, m i R N A_{N_{m i}}\right]^{T} \\
b=\left[b_{0}, b_{0}, \ldots, b_{0}\right]^{T}
\end{gathered}
$$

Elements $A_{j i}$ of matrix $A$ are equal to the impacts of $m i R N A_{i}$ on $m R N A_{j}$. Matrix $A$ is the product of matrix $C^{\prime}$ composed of elements reflecting the numbers of motifs recognized by different miRNAs (a simple example is shown in Fig. 3) and a diagonal matrix reflecting the concentration of these miRNAs. The matrix was validated by comparison with 3 differently randomized matrices: (Additional file 4: Figure S2): (1) simulated 


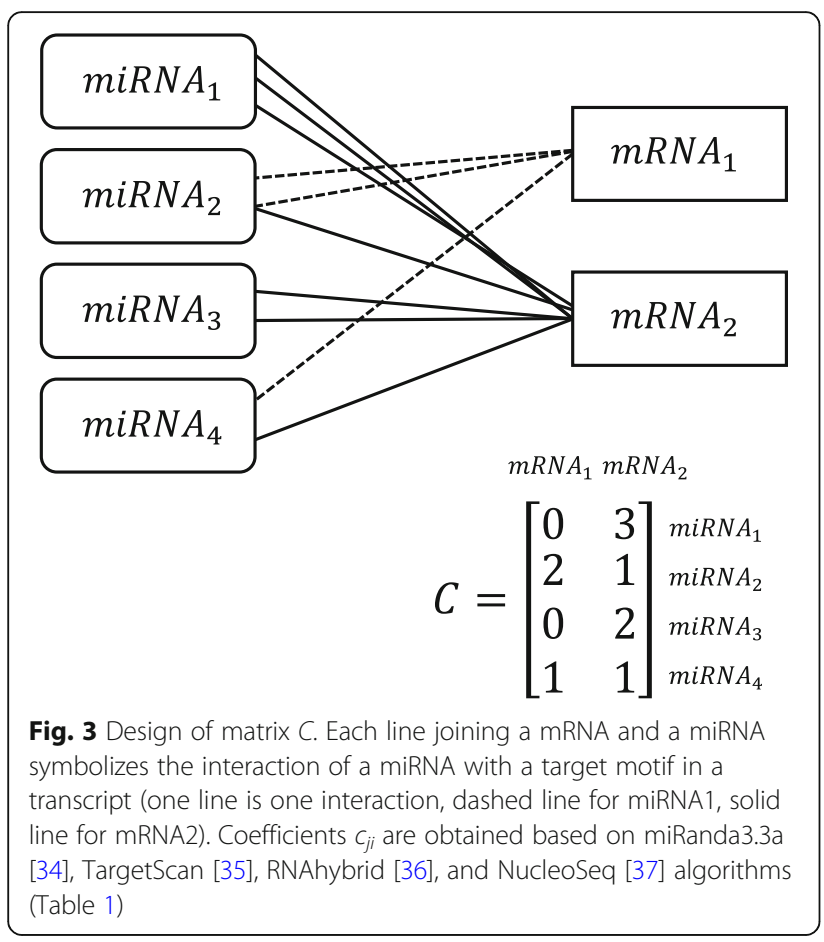

matrix $C$ with numbers drawn from the uniform distribution from the $[0,1]$ interval, (2) permuted databases-based $C$ matrix, (3) permuted $C$ matrix with model parameters estimated based on the original $C$ matrix. This model is simple, but it is useful only if the values of parameter $\Delta k$ are known, otherwise the mRNA fold change values cannot be calculated.

Matrix Equation (7), after substituting in the left side the experimentally observed fold changes of mRNA expressions $\left(F C m R N A^{\text {exp }}\right)$, constitutes a set of $N_{m}$ equations with $N_{m i}$ unknown coefficients $\Delta k_{i}$. There are more equations than coefficients and they are algebraically inconsistent because of the limited accuracy of microarray estimation of mRNA and miRNA levels and the fact that not all mRNA expressions are regulated by
miRNA. On the other hand, Equations (7) are linear with respect to the coefficients $\Delta k_{i}$, which therefore can be estimated using the Least Squares Method. The calculated $\Delta k_{i}$ values for all miRNAs expressed in Me45, K562, HCT116 ${ }^{+/+}$and HCT116 ${ }^{-/-}$cells together with other characteristics of the miRNAs are shown in Additional file 5: Table S3.

\section{Results}

Comparing model simulations to experimental data validation of the model

Estimated values of parameters $\Delta k_{i}$ were used in the model to predict the irradiation-induced mRNA changes and to compare the model calculations to the experimentally measured fold changes of mRNA expressions after irradiation in Me45, K562, $\mathrm{HCT}_{116}{ }^{+/+}$and HCT116 $6^{-1-}$ cells (Fig. 4). The Spearman's correlation coefficient between the predicted and experiment-based fold changes of mRNAs was 0.612 for Me45 cells. It indicates that the miRNA-based regulation assumed in the model has a significant impact on the post-irradiation mRNA profiles. The components of the parameter vector $\Delta k$, which characterize the influence of particular miRNAs on the change of the expression of a mRNA, differ among cell lines. This suggests that $\Delta k$ and the predicted results may be influenced by differences in the sets and properties of expressed mRNAs among these cell lines. For example, the motifs targeted by a particular miRNA could vary or have different accessibility in different cell lines..

To estimate the influence of the mRNA profile on parameter vector $\Delta k$ and the quality of model predictions, we divided the dataset of mRNA expressions into two random subsets. These are called the training set and validation set. Parameters estimated using the training set were then used to predict the miRNA-dependent mRNA expressions using the validation set. Resulting miRNA-mRNA scatterplots and histograms are depicted in Fig. 5 (Me45 cell line) and in Additional file 5: Table

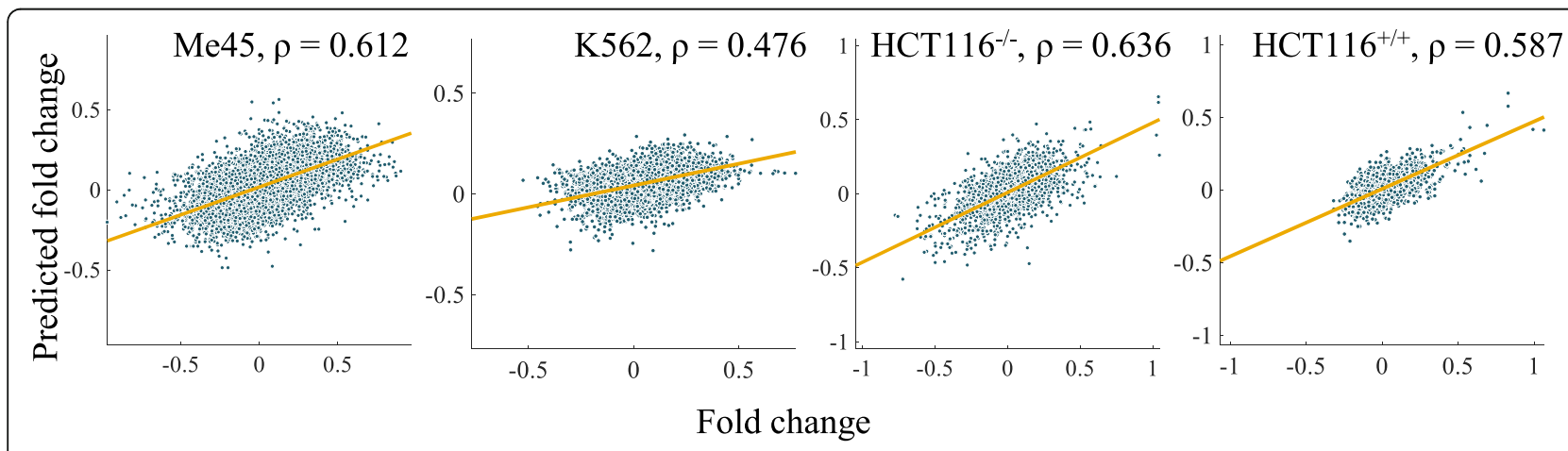

Fig. 4 Scatterplots demonstrating correlations between the predicted and the experimentally observed fold changes of mRNA levels in four cell lines experimentally studied by us 

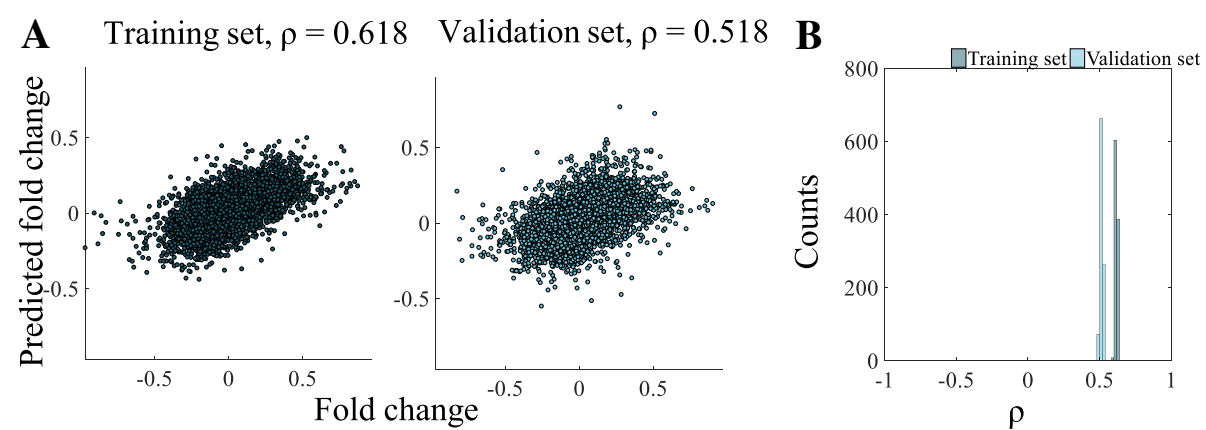

Fig. 5 Model validation for the Me45 cell data. The mRNA dataset was randomly split into the training and validation set and parameters $\Delta k$ were estimated based on the training set, and then applied to generate model predictions based on the validation subset. Depicted are the scatterplots of empirical vs. predicted mRNA fold changes in training (a) and validation (b) datasets, and the histograms of the corresponding correlation coefficients (c) based on 10,000 random splits

S3 (other cell lines). Scatter plots show the relation between experimental mRNA fold change values and those resulting from modelling for one example of training and validation set. The values of correlation coefficients are high: 0.618 and 0.518 , for the training and validation sets correspondingly. Similar values were obtained for 1000 random datasets, as shown in the histogram.

In the Affymetrix microarrays a significant proportion of transcripts has been present more than once (43\% in Me45 cell line, Additional file 6: Figure S3). Since the multiple readings of transcripts of the same gene have highly correlated expression levels, this may result in inflation of the empirical correlation coefficient. Therefore, for the final analysis (Fig. 5 and Additional file 3: Table S2) the superfluous expression levels have been removed. The adjusted (based on genes) and raw (based on transcripts) correlation coefficients are depicted in Additional file 3: Table S2.

As described in the Methods, we also ran our model on different datasets available in public databases including a variety of normal and cancer-related cell lines (see Methods for detail). Cells were irradiated with different ionizing radiation doses and the transcriptomes were assayed at different times after irradiation (see in Additional file 7: Figure S4 and Additional file 3: Table S2). Additional file 3: Table S2 summarizes properties of each dataset (number of expressed mRNAs and miRNAs), experimental conditions (radiation dose in Gy, time of observation) and results of model simulations described as Spearman correlation coefficient values.

\section{Different groups of miRNAs have positive or negative effects on mRNA expressions in irradiated cells}

The sign of parameter $\Delta k_{i}$ indicates increase (-) or correspondingly decrease $(+)$ amplitude of negative control of the expression of a corresponding mRNA by the $i$-th miRNA. The relationship between $\Delta k_{i}^{\prime}$ s sign and the structure of a miRNA may provide insights into modifications of miRNAs which occur after irradiation of cells. We classified all miRNAs into two subgroups based on the sign of parameter $\Delta k_{i}$ and compared their features, such as length, GC content, number of unpaired bases in the secondary structure of the corresponding pre-miRNA, and other features (see Additional file 5: Table S3 in Supplementary Material). We then performed Mann-Whitney U tests to check if the two samples originate from the same population. Table 2 compares the average values of some of these features calculated for all miRNAs and the subgroups characterized by negative or positive values of $\Delta k_{i}$. Cell line Me45 is used as the reference since statistically significant differences have been found only for this cell line. In general, miRNAs in the $\Delta k_{i}$-positive subgroup targeted a larger number of transcripts but had lower expression levels than miRNAs in the $\Delta k_{i}$-negative subgroup. However, most features had similar values in both subgroups and in most cases, the differences between the subgroups were not statistically significant. The exceptions are the GC content in miRNA ( $p$-value 0.003 ) and the seed motif ( $p$-value 0.02 ).

\section{Particular miRNAs are significant for changes of mRNA expressions after irradiation}

We decided to examine if all miRNAs had the same impact on changes of the global mRNA population in irradiated cells and, if this was not the case, how many miRNAs were sufficient to obtain the best correlation between predictions of our model and the experimental data. The contribution of particular miRNAs to modulation of the expressions of different mRNAs is reflected by the parameters $\Delta k_{i}$, and to answer the question asked we proceeded according to the algorithm depicted in Fig. 6a. As before, Me45 cell line is used as reference, with results for the remaining cell lines detailed in the Supplement.

The first step was to consider miRNAs one-by-one, to calculate fold changes of mRNA expressions predicted 
Table 2 Features of miRNA subgroups with negative or positive $\Delta k_{i}$, with Me45 cells as reference

\begin{tabular}{|c|c|c|c|c|c|c|}
\hline \multirow[t]{2}{*}{ Features } & \multicolumn{3}{|l|}{ Me45 cells } & \multicolumn{3}{|c|}{ Concordance in other cell lines } \\
\hline & $\begin{array}{l}\text { Average over miRNAs } \\
\text { with positive } \Delta k_{i}\end{array}$ & $\begin{array}{l}\text { Average over } \\
\text { all miRNAs }\end{array}$ & $\begin{array}{l}\text { Average over miRNAs } \\
\text { with negative } \Delta k_{i}\end{array}$ & K526 & $\mathrm{HCT} 116^{+/+}$ & $\mathrm{HCT} 116^{-1-}$ \\
\hline Length of pre-miRNA & 86.02 & 86.55 & 87.18 & + & - & - \\
\hline Hairpin length & 45.72 & 46.00 & 46.33 & + & - & - \\
\hline Length of mature miRNA & 21.66 & 21.61 & 21.56 & + & + & - \\
\hline GC content in miRNA & $54.59^{b}$ & 52.60 & $50.24^{b}$ & + & - & + \\
\hline GC content in seed motif & $56.06^{\mathrm{b}}$ & 53.93 & $51.40^{\mathrm{b}}$ & + & - & + \\
\hline Number of targeted transcripts ${ }^{\text {a }}$ & 3807.92 & 3711.41 & 3597.03 & + & + & + \\
\hline Expression level (logarithmic) & 4.43 & 4.52 & 4.63 & + & + & + \\
\hline
\end{tabular}

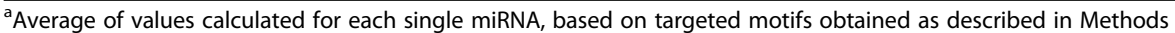

${ }^{\mathrm{b}}$ Boldface numbers indicate statistically significant differences

Plus sign indicates concordance (i.e., sign of the difference of feature averaged over miRNAs with positive and negative $\Delta k_{i}$, the same as in Me 45 cells); minus sign - lack of concordance

from the $\Delta k_{i}$ parameters, and to compare these to the experimental data. Calculations were repeated for each miRNA using Me45 cell data, and rank was ascribed to each miRNA based on the Spearman correlation coefficient between predicted and experimental results. The highest ranked 30 miRNAs with their parameters $\Delta k_{i}$. and the corresponding Spearman correlation coefficients are shown in Table 3. Results for all miRNAs are presented in Additional file 5: Table S3 of Supplementary Material. Ranks reflect the predicted influence of particular miRNAs on changes of the global mRNA expression in irradiated cells.

The value of parameter $\Delta k_{i}$ (negative or positive) did not appear to be correlated with miRNA rank; for example, for the highest ranked miR-762, $\Delta k_{i}$ is negative and its absolute value is one of the lowest. Twenty-two of the 30 top-ranked miRNAs are characterized by negative $\Delta k_{i}$, indicating that irradiation of cells tends to cause a decrease of the expression of the mRNAs with which they interact. Correlations of the model calculated
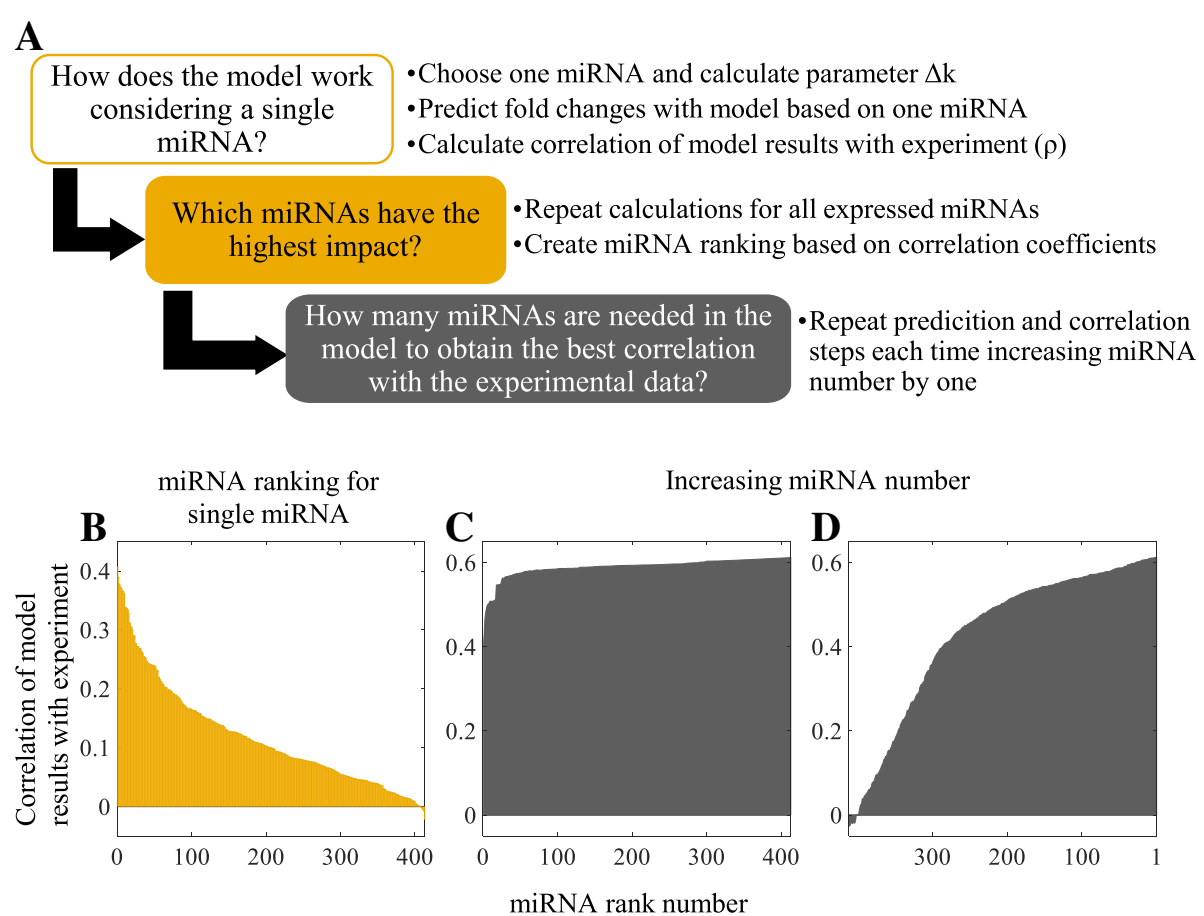

Fig. 6 Influence of individual miRNAs on the prediction of radiation-induced changes of mRNA levels in Me45 cells. a Steps in establishing the significance of particular miRNAs in radiation-induced changes of mRNA levels. $\mathbf{b}$ Ranking miRNA according to correlation coefficient from highest to lowest. c Using an increasing number of miRNAs added ordered by decreasing rank. $\mathbf{d}$ Using an increasing number of miRNAs added ordered by increasing rank 
Table 3 Highest ranking miRNAs (Me45 cells)

\begin{tabular}{|c|c|c|c|}
\hline Rank & miRNA & Correlation coefficient $\rho$ & Parameter $\Delta k_{i}$. \\
\hline 1 & hsa-miR-762 & 0.4067 & -0.00192 \\
\hline 2 & hsa-miR-638 & 0.3885 & -0.01268 \\
\hline 3 & hsa-miR-4281 & 0.3777 & -0.00403 \\
\hline 4 & hsa-miR-3648 & 0.3763 & -0.01113 \\
\hline 5 & hsa-miR-1247-5p & 0.3718 & -0.0154 \\
\hline 6 & hsa-miR-1207-5p & 0.3709 & -0.00183 \\
\hline 7 & hsa-miR-1469 & 0.3671 & -0.02113 \\
\hline 8 & hsa-miR-663a & 0.3656 & 0.00038 \\
\hline 9 & hsa-miR-1914-3p & 0.3647 & -0.00879 \\
\hline 10 & hsa-miR-2861 & 0.3612 & -0.00248 \\
\hline 11 & hsa-miR-1915-3p & 0.3386 & -0.00143 \\
\hline 12 & hsa-miR-122-5p & 0.3373 & -0.0073 \\
\hline 13 & hsa-miR-1268a & 0.3372 & 0.00116 \\
\hline 14 & hsa-miR-744-5p & 0.3356 & 0.01103 \\
\hline 15 & hsa-miR-362-3p & 0.3334 & -0.01466 \\
\hline 16 & hsa-miR-3656 & 0.3276 & 0.00076 \\
\hline 17 & hsa-miR-3141 & 0.3123 & -0.00158 \\
\hline 18 & hsa-miR-548f & 0.3101 & 0.01264 \\
\hline 19 & hsa-miR-663b & 0.3050 & -0.00226 \\
\hline 20 & hsa-miR-874 & 0.3038 & -0.00104 \\
\hline 21 & hsa-miR-1226-5p & 0.3001 & -0.01623 \\
\hline 22 & hsa-miR-3196 & 0.2900 & -0.00271 \\
\hline 23 & hsa-miR-1470 & 0.2899 & -0.00797 \\
\hline 24 & hsa-miR-1181 & 0.2893 & -0.00358 \\
\hline 25 & hsa-miR-548a-5p & 0.2769 & 0.0026 \\
\hline 26 & hsa-miR-320a & 0.2761 & 0.00804 \\
\hline 27 & hsa-miR-4270 & 0.2716 & -0.00057 \\
\hline 28 & hsa-miR-23a-5p & 0.2715 & -0.01881 \\
\hline 29 & hsa-miR-340-5p & 0.2713 & 0.00919 \\
\hline 30 & hsa-miR-296-3p & 0.2684 & -0.02642 \\
\hline
\end{tabular}

mRNA changes with only one miRNA assumed active using the experimental data are presented in Fig. 6b, where the $x$-axis shows the rank of the miRNA used in particular calculation and the y-axis the Spearman's correlation coefficient for the predicted and experimental results. The names of the miRNAs considered are found in Additional file 5: Table S3.

We addressed the question of how many miRNAs are necessary to obtain the highest correlation between the predicted and experimental results. The number of miRNAs used in the model was increased by one in successive steps and the calculated mRNA expressions were compared to the microarray results (Fig. 6c, d). The $\mathrm{y}$-axis shows the correlation coefficients and the $\mathrm{x}$-axis the rank numbers of the miRNA which was added to calculations in the model to compare with the previous calculation with a lower miRNA number. Figure $6 c$ shows the results when successive miRNAs were included in the calculations ordered by the decreasing rank. For example number 2 on the $\mathrm{x}$-axis indicates that in the model two miRNAs, 1 and 2 from the rank table, were included, and number 3 that the three miRNAs numbers 1,2 , and 3 from the rank table were included. Thus the correlation coefficient corresponding to number 2 on the $x$-axis refers to the hsa-miR-762 and hsa-miR-638 miRNAs (numbers 1 and 2 in rank, Table 3 ). In the case of these two miRNAs the correlation coefficient was 0.44 , and it increased with the number of miRNAs included ( 0.471 for 3 miRNAs, 0.483 for 4 miRNAs, 0.495 for 5 miRNAs and so forth). For more than 30 miRNAs the correlation coefficient reached a plateau value of about 0.56 . These results show that it is possible to obtain the maximum correlation between the model and the experimental data by considering only about 30 highest ranking miRNAs. We observed similar cumulative miRNA effects in other cell types (Additional file 8: Figure S5).

To examine to what extent this effect of saturation depends on the ordering of miRNA, we reversed the order of miRNA addition starting from those with the lowest rank (implicitly, with the lowest impact on predictions) and then adding miRNAs with increasing ranks (Fig. 6c). In this case, the correlation between model predictions and experimental values increased with increased miRNA number but reached a maximum value only when all miRNAs were included, suggesting that the miRNAs with highest ranks exert the highest impact on mRNA expression.

\section{Structural features of miRNAs with the highest impact on mRNA expressions}

To characterize the subgroup of 30 highest-ranked miRNAs, we compared different structural features of these miRNAs with all remaining miRNAs and performed Mann-Whitney $U$ tests to assess the significance of the differences. Results for the features statistically significant in Me45 and other cells are summarized in Table 4; the results for other features are summarized in Additional file 5: Table S3).

The influence of ionizing radiation on mRNA expressions might depend not only on structural features of transcripts, but also on features of miRNAs; for example, irradiation could influence interactions between miRNAs and other components of RISC complexes. We chose features potentially important for binding of pre-miRNA to Argonaute and/or other RISC proteins. These include pre-miRNA length, length of mature miRNA, nucleotide composition and hairpin length, and degree of complementarity. We also included structural features that might directly influence miRNA-mRNA interactions, 
Table 4 Properties of the 30 highest-ranked miRNAs compared with the group of all other miRNAs, with Me45 cells as reference

\begin{tabular}{|c|c|c|c|c|c|c|c|}
\hline \multirow[t]{2}{*}{ Features } & \multicolumn{3}{|l|}{ Me45 Cells } & \multicolumn{4}{|c|}{ Top rank vs. other miRNA $p$-value } \\
\hline & $\begin{array}{l}\text { Average over } \\
\text { all miRNAs }\end{array}$ & $\begin{array}{l}\text { Average over top } \\
\text { ranked miRNAs }\end{array}$ & $\begin{array}{l}\text { Average over } \\
\text { other miRNAs }\end{array}$ & Me45 & K562 & $\mathrm{HCT} 116^{+/+}$ & $\mathrm{HCT} 116^{-1-}$ \\
\hline $\begin{array}{l}\text { Number of total targeted } \\
\text { transcripts }{ }^{\text {a }}\end{array}$ & 3711.41 & 5523.86 & 3574.53 & $1.56 \times 10^{-10 b}$ & $1.00 \times 10^{-16 b}$ & $3.20 \times 10^{-09 b}$ & $7.17 \times 10^{-08 b}$ \\
\hline $\begin{array}{l}\text { GC content in mature } \\
\text { miRNA [\%] }\end{array}$ & 52.60 & 70.72 & 51.23 & $7.95 \times 10^{-09 b}$ & $3.26 \times 10^{-11 b}$ & $1.35 \times 10^{-05 b}$ & $0.001^{b}$ \\
\hline $\begin{array}{l}\text { GC content in seed motif } \\
{[\%]}\end{array}$ & 53.93 & 71.92 & 52.57 & $1.93 \times 10^{-07 b}$ & $1.23 \times 10^{-11 b}$ & $8.37 \times 10^{-05 b}$ & $0.002^{b}$ \\
\hline $\begin{array}{l}\text { GC content in pre-miRNA } \\
{[\%]}\end{array}$ & 52.90 & 66.44 & 51.88 & $2.55 \times 10^{-07 b}$ & $1.08 \times 10^{-08 b}$ & $3.69 \times 10^{-05 b}$ & $0.004^{b}$ \\
\hline $\begin{array}{l}\text { Number of GC pairs in } \\
\text { pre-miRNA }\end{array}$ & 15.73 & 19.74 & 15.43 & $0.027^{b}$ & $0.001^{b}$ & $0.005^{b}$ & 0.306 \\
\hline $\begin{array}{l}\text { Number of unpaired } \\
\text { fragments in mature } \\
\text { double stranded miRNA }\end{array}$ & 2.60 & 3.14 & 2.57 & $0.019^{b}$ & 0.243 & 0.144 & 0.526 \\
\hline $\begin{array}{l}\text { Length of complementary } \\
\text { fragments in pre-miRNA }\end{array}$ & 5.81 & 4.69 & 5.90 & $0.012^{b}$ & $0.042^{b}$ & 0.072 & 0.654 \\
\hline Length of mature miRNA & 21.61 & 21.14 & 21.65 & $0.031^{b}$ & $0.028^{b}$ & 0.522 & 0.169 \\
\hline Parameter $\Delta k_{i}$ & 0.00031 & -0.0039 & -0.000042 & $0.022^{b}$ & $0.016^{b}$ & 0.047 & 0.103 \\
\hline Spearman's rho in ranking & 0.12 & 0.33 & 0.10 & $7.24 \times 10^{-20 ~ b}$ & $2.48 \times 10^{-20 ~ b}$ & $1.80 \times 10^{-20 b}$ & $4.73 \times 10^{-20 b}$ \\
\hline
\end{tabular}

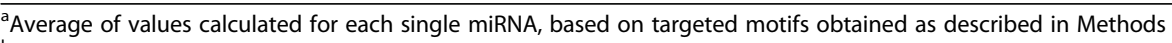

${ }^{\text {b } B o l d f a c e ~ n u m b e r s ~ i n d i c a t e ~ s t a t i s t i c a l l y ~ s i g n i f i c a n t ~ d i f f e r e n c e s ~}$

such as seed nucleotide composition, and total number of targeted transcripts. We then compared the average numerical characteristics in the top-ranked and other miRNA groups (Table 4). All statistics were calculated using our custom tools and later used to compare the top ranked to all other miRNA groups based on their average values. The features were selected based on Me45 cell line results, using the $p$-value $<0.05$ criterion. For completeness, results on the remaining cell lines were included in the Table 4.

The 30 highest-ranked miRNAs have a significantly higher content of $\mathrm{G}$ and $\mathrm{C}$ particularly in their seed motifs, they target a higher number of transcripts, and show a higher expression level than other miRNAs. In addition, the 30 highest-ranked miRNAs show features of the secondary structure of pre-miRNA such as length of complementary fragments (Table 4) and of the double-stranded form of mature miRNA, which suggest that the highest-ranked miRNAs differ from the other miRNAs also in this respect.

\section{Cellular processes influenced by the highest ranked miRNAs}

We identified the KEGG pathways terms corresponding to genes with transcripts containing sequence motifs targeted by the 30 top-ranked miRNAs. Table 5 shows the example of pathways for Me45 cells. We used DIANAmirPath [45] to find these pathways, but it was not possible to find detailed information about miRNAs which have been discovered only recently. The top-ranked

Table $\mathbf{5}$ Selected pathways regulated by the 30 highest-ranked miRNAs

\begin{tabular}{llll}
\hline KEGG pathway & $p$-value & Number of genes & Number of miRNAs \\
\hline Hippo signaling pathway & 0.00003 & 67 & 12 \\
Transcriptional misregulation in cancer & 0.0003 & 82 & 14 \\
Circadian rhythm & 0.0022 & 20 & 7 \\
Endocytosis & 0.0033 & 93 & 14 \\
ErbB signaling pathway & 0.0048 & 43 & 13 \\
TGF-beta signaling pathway & 0.0117 & 38 & 12 \\
mTOR signaling pathway & 0.0117 & 32 & 13 \\
Wnt signaling pathway & 0.0119 & 65 & 13 \\
Hedgehog signaling pathway & 0.0242 & 27 & 13 \\
FoxO signaling pathway & 0.0270 & 60 & 10 \\
\hline
\end{tabular}


miRNAs target mRNAs in 35 KEGG pathways ( $p$-value < 0.05). Examples of these pathways are shown in Table 5 and all are presented in the (Additional file 9: Table S4).

Many of these pathways are connected with cellular signalling and responses in different diseases. Identified pathways are consistent with top-rank miRNAs being connected with irradiation response. For example, the Hippo signaling pathway ( $p$-value $3.65 \times 10^{-5}, 67$ genes, 12 miRNAs) is involved in the responses to cellular stresses, including mechanical stress, DNA damage, and oxidative stress, aimed at maintaining homeostasis at the cellular and organic levels [46]. In addition, FoxO signalling pathway ( $p$-value $0.027,60$ genes, 10 miRNAs) is important in the activation of the ATM pathway and the maintenance of genome integrity in response to DNA damage [47]. Finally, mTOR signalling pathway ( $p$-value 0.011, 32 genes, 13 miRNAs) is responsible for redox homeostasis and radiosensitivity [48].

\section{Features of mRNAs which better fit the model to indicate miRNA regulation}

To search for differences between mRNAs that fit and those which do not fit our model, based on the Me45 cell line, we compared a subset of structural features of mRNAs with expression changes that could or could not be predicted and of their genes. Features considered include the numbers of transcription factor binding sites in promoter regions, numbers of ARE motifs of various types in the 3'-UTRs of their primary transcripts, nucleotide composition (percentage of $\mathrm{G}$ and $\mathrm{C}$ ), and mRNA turnover rates. We divided all mRNAs into two groups based on how well their expression level changes are predicted by the model. The threshold has been defined in the terms of the difference between predicted and observed $\log _{2}$ fold change, at the arbitrary value of 0.5. We then compared the structural features of the mRNAs in these groups using a two sample $t$-test, which allowed us to identify the discriminating factors summarized in Table 6. The group of mRNAs whose levels change as predicted by the model tends to have longer 3' UTRs, fewer AU-rich regions, less MYC response elements in their promoters, and shorter turnover times.

The criteria for mRNA classification used in the calculations in Table 6 were chosen arbitrarily. To examine the influence of the classification method on the results, we calculated the differences while varying the cut-off values with a 0.1 interval. A higher value of the cut-off criteria resulted in a lower number of mRNAs that showed a good fit to the data. By increasing the cut-off value, we found increasing structural differences between mRNAs and genes in groups that showed good or poor fit. mRNAs that show a good agreement with the model were characterized by a lower number of transcription factor binding sites and longer 3 '-ends (Additional file 10: Figure S6). This is consistent with regulation of some classes of mRNAs being more strongly influenced by transcription factors than by miRNAs.

\section{The influence of miRNA-mRNA interactions on response to radiation is cell type specific and depends on the radiation dose and time from irradiation}

In addition to the short-term $1 \mathrm{~h}$ time point we also explored, in less detail, the 12 and $24 \mathrm{~h}$ time points. The correlation coefficient between transcriptome changes predicted by the model and experimentally assayed changed in time suggesting that in Me45 cells the influence of miRNA-mRNA interactions on transcriptome changes decreased with time (Table 7).

Correlation coefficients between predicted and experimentally assayed mRNA expressions decreased with time in Me45 cells, which suggests that in this cell line these interactions had the highest influence on transcriptome changes directly after irradiation, and later the influence of other mechanisms increased. However for other cell types, the correlation coefficients of predictions versus the experimental results were not changing monotonously, and the patterns were cell type specific (see Table 7).

In addition, we performed analysis of experiments similar to ours, involving a set of cell types assayed at different times after irradiation. The datasets are available in the ArrayExpress database; some of their characteristics are listed in Additional file 1: Table S1. The correlation coefficients between experiment and our model prediction are always less than 1 since factors different from miRNAs influence the mRNA expressions and reduce the correlation. The correlation coefficients

Table 6 Features characterizing mRNAs with good or poor fit to the model, with Me45 cells as reference

\begin{tabular}{|c|c|c|c|c|c|c|}
\hline \multirow[t]{2}{*}{ Feature } & \multicolumn{2}{|c|}{ Me45 Cells: Average over } & \multicolumn{4}{|c|}{ Good vs. poor fit $p$-value } \\
\hline & Good fit & Poor fit & Me45 & K562 & $\mathrm{HCT} 116^{+/+}$ & $\mathrm{HCT} 116^{-/-}$ \\
\hline 3'-UTR average length [nucleotides] & 1466.3 & 1229.2 & $7.23 \times 10^{-06 b}$ & $0.007^{b}$ & 0.106 & 0.117 \\
\hline Average turnover time [h] & 7.912 & 8.766 & $0.0030^{b}$ & $0.027^{b}$ & 0.609 & 0.829 \\
\hline Average number of ARE consensus motifs/gene & 0.217 & 0.263 & $0.0291^{b}$ & 0.791 & $7.19 \times 10^{-05 b}$ & $0.004^{b}$ \\
\hline MYC response elements / gene & 1.434 & 1.561 & $0.0004^{b}$ & $0.003^{b}$ & 0.079 & $0.030^{b}$ \\
\hline
\end{tabular}

${ }^{\mathrm{b}}$ Boldface numbers indicate statistically significant differences 
Table 7 The correlation coefficients $(\rho)$ of model predicted and experimentally assayed transcriptome expressions change in time. Me45, K562 and HCT116 cells were irradiated with 2Gy of ionizing radiation, the levels of transcripts were assayed at different time points after irradiation in microarray experiment and predicted by model simulations

\begin{tabular}{|c|c|c|c|}
\hline \multirow[t]{2}{*}{ Cell lines } & \multicolumn{3}{|c|}{ Correlation coefficient $(\rho)$} \\
\hline & $1 \mathrm{~h}$ & $12 \mathrm{~h}$ & $24 \mathrm{~h}$ \\
\hline Me45 & 0.612 & 0.550 & 0.336 \\
\hline K562 & 0.476 & 0.356 & 0.414 \\
\hline $\mathrm{HCT} 116^{+/+}$ & 0.587 & 0.645 & 0.688 \\
\hline HCT116 & 0.636 & 0.547 & 0.586 \\
\hline
\end{tabular}

may be treated as a measure of the role of miRNA in regulation of mRNA expressions after action of stressing factor. Irradiated cells for which we performed model simulations differed with respect to correlation coefficient values. Accordingly, for estimation of the impact of miRNA-mRNA interactions on the response to radiation we used the threshold for good and poor fit classification based on the correlation coefficient greater or less than 0.2. As seen in Additional file 3: Table S2, some results do not pass this criterion suggesting that transcriptome changes in these experiments are not connected to changes of miRNA-mRNA interaction change.

Values of the correlation coefficient $(\rho)$ have been calculated for experimental and simulation data for each irradiation dose. A summary of results is depicted in Fig. 7. Bars represent mean values with minimal and maximal values calculated based correspondingly on 3

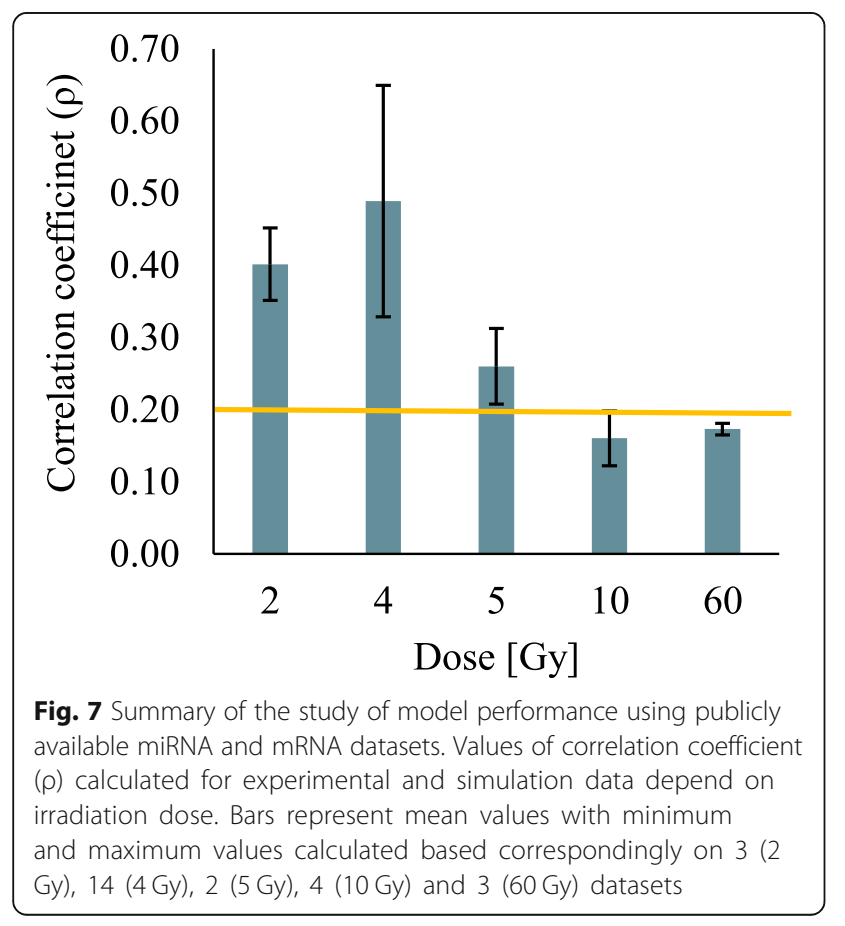

datasets with 2 Gy radiation dose, 14 with 4 Gy, 2 with 5 Gy, 4 with $10 \mathrm{~Gy}$, and 3 with $60 \mathrm{~Gy}$. Comparisons of predicted and experimental results for data available in the ArrayExpress database, involving cells irradiated with different doses, showed that a good fit between model and experiment is only achieved for doses lower than 5 Gy. Concluding, it seems that the regulation of mRNA expressions in irradiated cells depends on miRNA only if the direct effects of irradiation dominate cell response.

\section{Discussion}

As it is known, one major effect of ionizing radiation on cells is the induction of a massive wave of reactive oxygen species (ROS) which precedes the changes in mRNA expressions by a few minutes [30]. The results reported here are consistent with the hypothesis that these rapid changes in mRNA expressions result, at least in part, from damage to miRNAs and mRNAs by ROS which leads to perturbation of their interactions. It is not generally recognized that RNA is even more sensitive than DNA to oxidative damage [49]; the effects of ROS on RNA have been less explored, but in HeLa cells exposed to sub-milimolar concentrations of $\mathrm{H}_{2} \mathrm{O}_{2}$ for $1 \mathrm{~h}$, they led to a $50 \%$ decrease in the level of 8 -oxoG in total RNA (reviewed in [50]). In our top-ranked miRNAs which seem to influence mRNA expressions most, the seed region is significantly enriched in $\mathrm{GC}$; $\mathrm{G}$ has the lowest ionizing potential of the nucleic acid bases and G-specific damage by ROS is well documented for DNA and is therefore likely for RNA [51]. mRNAs whose primary transcripts contain a longer than average CUG repeat in their 3'UTR might be more sensitive to down-regulation by miRNAs which bind to them, as observed for regulation of the myotonic dystrophy protein kinase (DMPK) gene by miR-15b/16 where an increased number of CUG repeats increases the efficiency of down-regulation [52]. Our model summarizes the effects of all available miRNAs on each particular mRNA, assuming that the effects depend on the number of different miRNA-targeted sequences and the miRNA concentrations. Some transcripts contain a large number of possible miRNA binding sites; for example, the MDM2 and MDM4 transcripts have 760 and 1276 potential miRNA binding sites, respectively [53]. How many of these sites are active, seems unclear.

It is notable that a specific group of thirty miRNAs is predicted to be mainly responsible for the observed miRNA-dependent mRNA changes in irradiated cells. These are the miRNAs sufficient for obtaining a maximal correlation between the predicted and experimental results. Fifteen of the 30 top-ranked miRNAs participate in cellular processes involved in cancer development and metastasis. The one highest-ranked in Me45 cells, miRNA-762, promotes breast cancer cell proliferation 
and invasion [54] and the second, miR-638, plays a role in embryonic development and tissue differentiation [55-58] and is involved in the development of numerous types of tumors including gastric cancer [59-62], colorectal carcinoma [63, 64], non-small cell lung cancer [65, 66], basal cell carcinoma [67], nasopharyngeal carcinoma [68], and melanoma [69]. Expressions of the high-ranked miRNAs 3648, 663a and b, $548 \mathrm{t}$, miR-1207, 1225-5p, 3141, and 4270 (Table 3) are correlated with breast cancer recurrence and prostate cancer metastasis [70, 71].

We note that our model has some limitations. First, it considers only one of several regulatory mechanisms that could be perturbed by radiation, and therefore it is not expected to reproduce all changes in mRNA expressions. mRNA expressions depend not only on interactions with miRNAs but also on their transcription rate and half-lives, both of which could be affected by radiation. Other more complex processes which are not considered in our model could potentially contribute to the response of the level of a mRNA to irradiation, including effects on only some of the miRNA-transcript interactions which regulate its level [52] or opposing effects which result in no change in level. Transcripts which contain targets for miRNAs separated by $7-40$ bases and therefore with a greater possible cooperativity may be more sensitive to down-regulation, as observed for the effects of miR-148a and miR-206 on mRNA transcribed from the DMPK gene [52, 72]. Further examples of increased sensitivity to down-regulation include decoybased relief of mRNA repression by miRNA [72, 73], competitive endogenous RNAs (ceRNAs) which bind miRNAs, specific pseudogenes which relieve miRNAbased repression of mRNAs [72, 74-78], or the influence of AU-rich binding proteins such as HuR [72, 73]. These exceptions, which are uncommon relative to the miRNA binding considered in our model, do not seriously affect the validity of our modelling approach.

The second limitation is that only degradation of mRNAs can be detected by microarrays but not inhibition of mRNA translation, and in no case we do obtain a full correlation between the fold changes of mRNA expressions predicted by the model and data from microarrays. Nevertheless, the changes of mRNA expressions predicted by this model show high correlation coefficients (ca. 0.6) with experimental data and are statistically significant. Our modeling approach thus appears to reflect real relationships which occur in vivo, and suggests that a part of the ionizing radiation-induced changes of mRNA expressions depends on perturbed miRNA-mRNA interactions. This modeling approach could be used to identify miRNAs which participate in responses of cells to other environmental challenges.

\section{Additional files}

Additional file 1: Table S1. Summary of dataset at our disposal downloaded from ArrayExpress database. Table includes information about tissue and cell names, experimental settings and microarray platform and ID numbers of individual experiments. (XLSX $10 \mathrm{~kb}$ )

Additional file 2: Figure S1. Model prediction (correlation coefficient value between experimental and simulation data $\rho$ ) for different noise level thresholds for mRNA in microarray data. Three thresholds were tested 4 ( 1700 mRNAs), 6 ( 1000 mRNAs) and 8 ( 500 mRNAs), as described in Measurement of mRNA and miRNA levels section. (TIF $80 \mathrm{~kb}$ )

Additional file 3: Table S2. Summary of each dataset (number of expressed mRNAs and miRNAs), experimental conditions (radiation dose in Gy, time of observation) and results of model simulations and validation described as Spearman correlation coefficient values for all analysed cell lines. (XLSX $14 \mathrm{~kb}$ )

Additional file 4: Figure S2. Three methods for C matrix validation. A) Each value in $C$ matrix is represented by random number. Numbers were drawn from uniform distribution [0-1]. Resulting $C$ matrix was used to simulate predicted mRNA fold change. Example of single prediction is presented on the left in the form of scatter plot, a result of thousand predictions is presented on the right in the form of histogram, where $x$ axes indicated $\rho$ returned by model. B) The $C$ matrix was permuted (the values change the initial location). Resulting $C$ matrix was used to

simulate predicted fold change. Example of single prediction is presented on the left in the form of scatter plot, a result of thousand predictions is presented on the right in the form of histogram, where $x$ axes indicated $\rho$ returned by model. C) Original C matrix was used to estimate model parameters, after that the $C$ matrix was permuted and used for prediction of mRNA changes. Example of single prediction is presented on the left in the form of scatter plot, a result of thousand predictions is presented on the right in the form of histogram, where $x$ axes indicated $\rho$ returned by model. (TIF $1058 \mathrm{~kb}$ )

Additional file 5: Table S3. The calculated values for all miRNAs expressed in Me45, K562, HCT116+/+ and HCT116-/- cells together with other characteristics of the miRNAs studied. (XLSX $345 \mathrm{~kb}$ )

Additional file 6: Figure S3. Proportion of genes represented by one or more transcripts in four cell lines. (TIF $561 \mathrm{~kb}$ )

Additional file 7: Figure S4. Correlations between the predicted and the experimentally observed fold changes of mRNA levels in all available cell lines. A) AG1522 cell line, $3 \mathrm{~h}$ after radiation, dose $2 \mathrm{~Gy}, \rho=0.378$. B) AG1522cell line, $3 \mathrm{~h}$ after radiation, dose $5 \mathrm{~Gy}, \rho=0.222$. C) MOLT4 (Bay) cell line, $2 \mathrm{~h}$ after radiation, dose $4 \mathrm{~Gy}, \rho=0.215$. D) MOLT4 (DMSO) cell line, $2 \mathrm{~h}$ after radiation, dose $4 \mathrm{~Gy}, \rho=0.196$. E) DU145cell line, $2 \mathrm{~h}$ after radiation, dose $10 \mathrm{~Gy}, \rho=0.172$. F) HCAEC (SD) cell line, $6 \mathrm{~h}$ after radiation, dose $10 \mathrm{~Gy}, \rho=0.108$. G) HCAECs (MF) cell line, $6 \mathrm{~h}$ after radiation, dose $10 \mathrm{~Gy}, \rho=0.198$. $\mathrm{H}$ ) MOLT4 cell line, $2 \mathrm{~h}$ after radiation, dose $5 \mathrm{~Gy}, \rho=0.297$. I) PBMC cell line, $2 \mathrm{~h}$ after radiation, dose $60 \mathrm{~Gy}$, $\rho=0.179$. J) PBMC cell line, $4 \mathrm{~h}$ after radiation, dose $60 \mathrm{~Gy}, \rho=0.163$. K) PBMC cell line, $20 \mathrm{~h}$ after radiation, dose $60 \mathrm{~Gy}, \rho=0.175$. L) SC3 cell line, $2 \mathrm{~h}$ after radiation, dose $10 \mathrm{~Gy}, \rho=0.160$. M) WI38 cell line, $1 \mathrm{~h}$ after radiation, dose $2 \mathrm{~Gy}, \rho=0.366$. N) WI39 cell line, $2 \mathrm{~h}$ after radiation, dose $2 \mathrm{~Gy}, \rho=0.459$ (TIF $812 \mathrm{~kb}$ )

Additional file 8: Figure S5. Influence of individual miRNAs on the prediction of radiation-induced changes of mRNA levels in K562 (A, B, C) HCT116+/+ (D, E, F) and HCT116-/- $(G, H, I)$ cells. (A, D, G) Ranking miRNA according to correlation coefficient to lowest. $(B, E, H)$ Using an increasing number of miRNAs added according to decreasing rank. (C, F, I) Using an increasing number of miRNAs added according to increasing rank. (TIF 878 kb)

Additional file 9: Table S4. KEGG pathways identified for 30 top-rank miRNAs in Me45 cell line. (XLSX 12 kb)

Additional file 10: Figure S6. Influence of the classification criteria on differences between mRNAs with good or poor fit to the model. The plot is an extended version of the data in Table 3, showing the same features but using variable fit error cutoffs for classification based on how well they fit the model. (TIF $182 \mathrm{~kb}$ ) 


\section{Abbreviations}

ceRNA: Competitive endogenous RNA; EM: Expectation-maximization; FC: Fold change; HCT116-/- : HCT116 p53 -/- cell line; HCT116 $6^{+/+}$: HCT116 p53+/+ cell line; K562: Human immortalised myelogenous leukemia cell line; Me45: Human melanoma cell line (established in the Center of Oncology Gliwice); miRNA: MicroRNA; mRNA: Messenger RNA; RISC: RNA-induced silencing complex; TF: Transcription factor

\section{Acknowledgements}

The Authors thank Ronald Hancock for stimulating discussions and help with the final version of the manuscript.

\section{Funding}

This work was supported by the Polish National Science Center, grant UMO2015/19/B/ST7/02984. Calculations were performed using the Ziemowit computational cluster (http://www.ziemowit.hpc.polsl.pl) funded by the EU Innovative Economy Program (POIG) project 02.01.00-00-166/08 (BIO-FARMA) and expanded under the POIG project 02.03.01-00-040/13 (Syscancer). Experiments were performed in the Silesian BIO-FARMA - Bioinformatics Laboratory and the Biotechnology Centre of the Silesian University of Technology (POIG.02.01.00-00-166/08 project).

\section{Availability of data and materials}

All microarray data files are available from ArrayExpress database (Me45, $\mathrm{K} 562, \mathrm{HCT} 116^{+/+}$and $\mathrm{HCT} 116^{-/-}$cell lines accession numbers E-MEXP-2623, and E-MTAB-5197 for mRNAs and miRNAs, respectively). ID for published datasets can be found in separate excel file (Additional file 1: Table S1).

\section{Authors' contributions}

JRW and KF conceived and designed the overall study, analysed and interpreted data and drafted the manuscript. $\mathrm{AL}$ and $\mathrm{KB}$ carried out experiments, MM, RJ, KB and MK analysed and interpreted data and contributed to drafting the manuscript. KF proposed model concept. MM and RJ implemented and simulated the model, and visualized obtained results. All authors read and approved the final manuscript.

\section{Ethics approval and consent to participate}

Not applicable.

\section{Consent for publication}

Not applicable.

\section{Competing interests}

The authors declare that they have no competing interests.

\section{Publisher's Note}

Springer Nature remains neutral with regard to jurisdictional claims in published maps and institutional affiliations.

\section{Author details}

'Department of Systems Engineering, Institute of Automatic Control, Silesian University of Technology, ul. Akademicka 16, 44-100 Gliwice, Poland. ${ }^{2}$ Ardigen S.A., ul. Bobrzyńskiego 14, 30-348, Cracow, Poland. ${ }^{3}$ Centre of Biotechnology, Silesian University of Technology, ul. Bolesława Krzywoustego 8, 44-100 Gliwice, Poland. ${ }^{4}$ Departments of Statistics and Bioengineering, Rice University, MS 138, 6100 Main, Houston, TX 77005, USA. ${ }^{5}$ Department of Medical and Molecular Biology, School of Medicine with the Division of Dentistry in Zabrze, Medical University of Silesia in Katowice, Katowice, USA

Received: 23 July 2018 Accepted: 21 January 2019

Published online: 06 February 2019

\section{References}

1. Jaksik R, Lalik A, Skonieczna M, Cieslar-Pobuda A, Student S, RzeszowskaWolny J. MicroRNAs and reactive oxygen species: are they in the same regulatory circuit? Mutat Res-Gen Tox En. 2014;764:64-71.

2. Bushati N, Cohen SM. microRNA functions. Annu Rev Cell Dev Biol. 2007;23: 175-205.

3. Leung AK, Sharp PA. MicroRNA functions in stress responses. Mol Cell. 2010; 40(2):205-15.
4. O'Connell RM, Rao DS, Baltimore D. microRNA regulation of inflammatory responses. Annu Rev Immunol. 2012;30:295-312.

5. Bartel DP. MicroRNAs: target recognition and regulatory functions. Cell. 2009:136(2):215-33.

6. Yin J, Bai Z, Song J, Yang Y, Wang J, Han W, et al. Differential expression of serum miR-126, miR-141 and miR-21 as novel biomarkers for early detection of liver metastasis in colorectal cancer. Chinese journal of cancer research = Chung-kuo yen cheng yen chiu. 2014;26(1):95-103.

7. Wang D, Gu J, Wang T, Ding Z. OncomiRDB: a database for the experimentally verified oncogenic and tumor-suppressive microRNAs. Bioinformatics. 2014;30(15):2237-8.

8. Mulrane L, Klinger R, McGee SF, Gallagher WM, O'Connor DP. microRNAs: a new class of breast cancer biomarkers. Expert Rev Mol Diagn. 2014;14(3): 347-63.

9. Stokowy T, Wojtas B, Fujarewicz K, Jarzab B, Eszlinger M, Paschke R. miRNAs with the potential to distinguish follicular thyroid carcinomas from benign follicular thyroid tumors: results of a meta-analysis. Hormone and metabolic research $=$ Hormon- und Stoffwechselforschung $=$ Hormones et metabolisme. 2014:46(3):171-80.

10. Stokowy T, Eszlinger M, Swierniak M, Fujarewicz K, Jarzab B, Paschke R, et al. Analysis options for high-throughput sequencing in miRNA expression profiling. BMC research notes. 2014;7:144.

11. Vera J, Lai $X$, Schmitz U, Wolkenhauer O. MicroRNA-regulated networks: the perfect storm for classical molecular biology, the ideal scenario for systems biology. Adv Exp Med Biol. 2013;774:55-76.

12. Lai X, Bhattacharya A, Schmitz U, Kunz M, Vera J, Wolkenhauer O. A systems' biology approach to study microRNA-mediated gene regulatory networks. Biomed Res Int. 2013:2013:703849.

13. Zinovyev A, Morozova N, Gorban AN, Harel-Belan A. Mathematical modeling of microRNA-mediated mechanisms of translation repression. Adv Exp Med Biol. 2013;774:189-224

14. Zinovyev A, Morozova N, Nonne N, Barillot E, Harel-Bellan A, Gorban AN. Dynamical modeling of microRNA action on the protein translation process. BMC Syst Biol. 2010;4:13

15. Morozova N, Zinovyev A, Nonne N, Pritchard LL, Gorban AN, Harel-Bellan A. Kinetic signatures of microRNA modes of action. RNA. 2012;18(9):1635-55.

16. Wang YP, Li KB. Correlation of expression profiles between microRNAs and mRNA targets using NCl-60 data. BMC Genomics. 2009:10:218.

17. van Iterson M, Bervoets S, de Meijer EJ, Buermans HP, PA TH, Menezes RX et al. Integrated analysis of microRNA and mRNA expression: adding biological significance to microRNA target predictions. Nucleic Acids Res. 2013;41(15):e146.

18. Li XH, Gill R, Cooper NGF, Yoo JK, Datta S. Modeling microRNA-mRNA interactions using PLS regression in human Colon Cancer. BMC Med Genet. 2011:4.

19. Fu J, Tang W, Du P, Wang G, Chen W, Li J, et al. Identifying microRNA$m R N A$ regulatory network in colorectal cancer by a combination of expression profile and bioinformatics analysis. BMC Syst Biol. 2012;6:68.

20. Ruike Y, Ichimura A, Tsuchiya S, Shimizu K, Kunimoto R, Okuno Y, et al. Global correlation analysis for micro-RNA and mRNA expression profiles in human cell lines. J Hum Genet. 2008:53(6):515-23.

21. Luo Z, Azencott $R$, Zhao $Y$. Modeling miRNA-mRNA interactions: fitting chemical kinetics equations to microarray data. BMC Syst Biol. 2014;8:19.

22. Bryan K, Terrile M, Bray IM, Domingo-Fernandez R, Watters KM, Koster J, et al. Discovery and visualization of miRNA-mRNA functional modules within integrated data using bicluster analysis. Nucleic Acids Res. 2014; 42(3):e17.

23. Engelmann JC, Spang R. A least angle regression model for the prediction of canonical and non-canonical miRNA-mRNA interactions. PLoS One. 2012; 7(7):e40634.

24. Guo L, Zhao Y, Yang S, Zhang H, Chen F. Integrative analysis of miRNAmRNA and miRNA-miRNA interactions. Biomed Res Int. 2014:2014:907420.

25. Jacobsen A, Silber J, Harinath G, Huse JT, Schultz N, Sander C. Analysis of microRNA-target interactions across diverse cancer types. Nat Struct Mol Biol. 2013;20(11):1325-32

26. Liu B, Li J, Tsykin A, Liu L, Gaur AB, Goodall GJ. Exploring complex miRNAmRNA interactions with Bayesian networks by splitting-averaging strategy. BMC bioinformatics. 2009:10:408.

27. Sales G, Coppe A, Bisognin A, Biasiolo M, Bortoluzzi S, Romualdi C. MAGIA, a web-based tool for miRNA and Genes Integrated Analysis. Nucleic Acids Res. 2010;38(Web Server issue):W352-9. 
28. Nam S, Li M, Choi K, Balch C, Kim S, Nephew KP. MicroRNA and mRNA integrated analysis (MMIA): a web tool for examining biological functions of microRNA expression. Nucleic Acids Res. 2009;37(Web Server issue):W356-62.

29. Ray R, Pandey P. Surveying computational algorithms for identification of miRNA-mRNA regulatory modules. The Nucleus. 2017;60(2\%@ 0976-7975): 165-74.

30. Herok R, Konopacka M, Polanska J, Swierniak A, Rogolinski J, Jaksik R, et al. Bystander effects induced by medium from irradiated cells: similar transcriptome responses in irradiated and bystander K562 cells. Int J Radiat Oncol Biol Phys. 2010;77(1):244-52.

31. Iwasaki S, Kawamata T, Tomari Y. Drosophila argonaute1 and argonaute2 employ distinct mechanisms for translational repression. Mol Cell. 2009; 34(1):58-67.

32. Kolesnikov N, Hastings E, Keays M, Melnichuk O, Tang YA, Williams E, et al. ArrayExpress update--simplifying data submissions. Nucleic Acids Res. 2015 43(Database issue):D1113-6.

33. Rzeszowska-Wolny J, Herok R, Widel M, Hancock R. X-irradiation and bystander effects induce similar changes of transcript profiles in most functional pathways in human melanoma cells. DNA repair. 2009;8(6): 732-8.

34. Irizarry RA, Hobbs B, Collin F, Beazer-Barclay YD, Antonellis KJ, Scherf U, et al. Exploration, normalization, and summaries of high density oligonucleotide array probe level data. Biostatistics. 2003;4(2):249-64.

35. Marczyk M, Jaksik R, Polanski A, Polanska J. Adaptive filtering of microarray gene expression data based on Gaussian mixture decomposition. BMC bioinformatics. 2013;14:101.

36. Riffo-Campos AL, Riquelme I, Brebi-Mieville P. Tools for Sequence-Based miRNA Target Prediction: What to Choose? Int J Mol Sci. 2016;17(12):1987.

37. John B, Enright AJ, Aravin A, Tuschl T, Sander C, Marks DS. Human MicroRNA targets. PLoS Biol. 2004;2(11):e363.

38. Lewis BP, Burge CB, Bartel DP. Conserved seed pairing, often flanked by adenosines, indicates that thousands of human genes are microRNA targets. Cell. 2005;120(1):15-20.

39. Kruger J, Rehmsmeier M. RNAhybrid: microRNA target prediction easy, fast and flexible. Nucleic acids research. 2006:34(Web Server issue):W451-4.

40. Jaksik R, Rzeszowska-Wolny J. The distribution of GC nucleotides and regulatory sequence motifs in genes and their adjacent sequences. Gene. 2012;492(2):375-81.

41. Gruber AR, Fallmann J, Kratochvill F, Kovarik P, Hofacker IL. AREsite: a database for the comprehensive investigation of AU-rich elements. Nucleic Acids Res. 2011;39(Database issue):D66-9.

42. Tani H, Mizutani R, Salam KA, Tano K, ljiri K, Wakamatsu A, et al. Genomewide determination of RNA stability reveals hundreds of short-lived noncoding transcripts in mammals. Genome Res. 2012;22(5):947-56.

43. Gerstein MB, Kundaje A, Hariharan M, Landt SG, Yan KK, Cheng C, et al. Architecture of the human regulatory network derived from ENCODE data. Nature. 2012;489(7414):91-100.

44. Peter ME. Targeting of mRNAs by multiple miRNAs: the next step. Oncogene. 2010;29(15):2161-4

45. Vlachos IS, Zagganas K, Paraskevopoulou MD, Georgakilas G, Karagkouni D, Vergoulis T, et al. DIANA-miRPath v3.0: deciphering microRNA function with experimental support. Nucleic Acids Res. 2015:43(W1):W460-6.

46. Mao B, Gao Y, Bai Y, Yuan Z. Hippo signaling in stress response and homeostasis maintenance. Acta Biochim Biophys Sin. 2015:47(1):2-9.

47. Tarrade S, Bhardwaj T, Flegal M, Bertrand L, Velegzhaninov I, Moskalev A, et al. Histone $\mathrm{H} 2 \mathrm{AX}$ is involved in FoxO3a-mediated transcriptional responses to ionizing radiation to maintain genome stability. Int J Mol Sci. 2015;16(12): 29996-30014

48. Zheng $\mathrm{H}$, Wang $\mathrm{M}$, Wu J, Wang ZM, Nan HJ, Sun H. Inhibition of mTOR enhances radiosensitivity of lung cancer cells and protects normal lung cells against radiation. Biochemistry and cell biology $=$. Biochimie et biologie cellulaire. 2016;94(3):213-20.

49. Wang WX, Luo SB, Xia MM, Mao YH, Zhou XY, Jiang $P$, et al. Analysis of the oxidative damage of DNA, RNA, and their metabolites induced by hyperglycemia and related nephropathy in Sprague Dawley rats. Free Radic Res. 2015;49(10):1199-209.

50. Li Z, Wu J, Deleo CJ. RNA damage and surveillance under oxidative stress. IUBMB Life. 2006;58(10):581-8.

51. Cadet J, Douki T, Gasparutto D, Ravanat J. Oxidative damage to DNA: formation, measurement and biochemical features. Mutat Res. 2003;531(1-2):5-23.
52. Koscianska E, Witkos T, Kozlowska E, Wojciechowska M, Krzyzosiak W. Cooperation meets competition in microRNA-mediated DMPK transcript regulation. Nucleic Acids Res. 2015:43(19):9500-18.

53. Hoffman $Y$, Pilpel $Y$, Oren $M$. microRNAs and Alu elements in the p53-Mdm2-Mdm4 regulatory network. J Mol Cell Biol. 2014;6(3): 192-7.

54. Li Y, Huang R, Wang L, Hao J, Zhang Q, Ling R, et al. microRNA-762 promotes breast cancer cell proliferation and invasion by targeting IRF7 expression. Cell Prolif. 2015;48(6):643-9.

55. Lin Y, Zeng Y, Zhang F, Xue L, Huang Z, Li WX, et al. Characterization of MicroRNA Expression Profiles and the Discovery of Novel MicroRNAs Involved in Cancer during Human Embryonic Development. PloS one. 2013; 8(8):e69230

56. Xie W, Li Z, Li M, Xu N, Zhang Y. miR-181a and inflammation: miRNA homeostasis response to inflammatory stimuli in vivo. Biochem Biophys Res Commun. 2013;430(2):647-52.

57. Lin Y, Li DJ, Liang Q, Liu SQ, Zuo XL, Li L, et al. miR-638 regulates differentiation and proliferation in leukemic cells by targeting cyclindependent kinase 2. J Biol Chem. 2015:290(3):1818-28.

58. Wu CR, Lin HT, Wang QL, Chen W, Luo HH, Chen WR, et al. Discrepant expression of MicroRNAs in transparent and Cataractous human lenses. Invest Ophthalmol Vis Sci. 2012;53(7):3906-12.

59. Yao Y, Suo AL, Li ZF, Liu LY, Tian T, Ni L, et al. MicroRNA profiling of human gastric cancer. Mol Med Rep. 2009;2(6):963-70.

60. Wang JL, Hu Y, Kong X, Wang ZH, Chen HY, Xu J, et al. Candidate microRNA Biomarkers in Human Gastric Cancer: A Systematic Review and Validation Study. PloS one. 2013;8(9):e73683.

61. Zhao LY, Yao Y, Han J, Yang J, Wang XF, Tong DD, et al. miR-638 suppresses cell proliferation in gastric Cancer by targeting Sp2. Digest Dis Sci. 2014; 59(8):1743-53.

62. Zhang JW, Bian ZH, Zhou JL, Song MX, Liu ZH, Feng YY, et al. MicroRNA-638 inhibits cell proliferation by targeting phospholipase D1 in human gastric carcinoma. Protein Cell. 2015;6(9):680-8

63. Kahlert C, Klupp F, Brand K, Lasitschka F, Diederichs S, Kirchberg J, et al. Invasion front-specific expression and prognostic significance of microRNA in colorectal liver metastases. Cancer Sci. 2011;102(10):1799-807.

64. Zhang J, Fei B, Wang Q, Song M, Yin Y, Zhang B, et al. MicroRNA-638 inhibits cell proliferation, invasion and regulates cell cycle by targeting tetraspanin 1 in human colorectal carcinoma. Oncotarget. 2014;5(23): $12083-96$.

65. Xia Y, Wu Y, Liu B, Wang P, Chen Y. Downregulation of miR-638 promotes invasion and proliferation by regulating SOX2 and induces EMT in NSCLC. FEBS Lett. 2014:588(14):2238-45.

66. Wang F, Lou JF, Cao Y, Shi XH, Wang P, Xu J, et al. miR-638 is a new biomarker for outcome prediction of non-small cell lung cancer patients receiving chemotherapy. Exp Mol Med. 2015;47:e162.

67. Sand M, Skrygan M, Sand D, Georgas D, Hahn SA, Gambichler T, et al. Expression of microRNAs in basal cell carcinoma. Br J Dermatol. 2012;167(4): 847-55.

68. Liu N, Cui RX, Sun Y, Guo R, Mao YP, Tang LL, et al. A four-miRNA signature identified from genome-wide serum miRNA profiling predicts survival in patients with nasopharyngeal carcinoma. Int J Cancer. 2014;134(6):1359-68.

69. Bhattacharya A, Schmitz U, Raatz Y, Schonherr M, Kottek T, Schauer M, et al. miR-638 promotes melanoma metastasis and protects melanoma cells from apoptosis and autophagy. Oncotarget. 2015:6(5):2966-80.

70. Hamam R, Ali AM, Alsaleh KA, Kassem M, Alfayez M, Aldahmash A, et al. microRNA expression profiling on individual breast cancer patients identifies novel panel of circulating microRNA for early detection. Scientific reports. 2016;6:25997.

71. Knyazev EN, Samatov TR, Fomicheva KA, Nyushko KM, Alekseev BY, Shkurnikov MY. MicroRNA hsa-miR-4674 in Hemolysis-Free Blood Plasma Is Associated with Distant Metastases of Prostatic Cancer. B Exp Biol Med+. 2016;161(1):112-5

72. Vasudevan S. Posttranscriptional upregulation by MicroRNAs. WIREs RNA. 2012;3:311-30

73. Letonqueze $\mathrm{O}$, Lee J, Vasudevan S. MicroRNA-mediated posttranscriptional mechanisms of gene expression in proliferating and quiescent cancer cells. RNA Biol. 2012:9(6):871-80.

74. Denzler R, Agarwal V, Stefano J, Bartel D, Stoffel M. Assessing the ceRNA hypothesis with quantitative measurements of miRNA and target abundance. Mol Cell. 2014;54(5):76-776. 
75. Saito T, Sætrom P. Target gene expression levels and competition between transfected and endogenous microRNAs are strong confounding factors in microRNA high-throughput experiments. Silence. 2012;3(3).

76. de Giorgio A, Krell J, Harding V, Stebbing J, Castellano L. Emerging roles of competing endogenous RNAs in Cancer: insights from the regulation of PTEN. Mol Cell Biol. 2013;33(20):3976-82.

77. Bosson AD, Zamudio JR, Sharp PA. Endogenous miRNA and target concentrations determine susceptibility to potential ceRNA competition. Mol Cell. 2014;56(3):347-59.

78. Broderick JA, Zamore PD. Competitive endogenous RNAs cannot alter microRNA function in vivo. Mol Cell. 2014;54(5):711-3.

Ready to submit your research? Choose BMC and benefit from:

- fast, convenient online submission

- thorough peer review by experienced researchers in your field

- rapid publication on acceptance

- support for research data, including large and complex data types

- gold Open Access which fosters wider collaboration and increased citations

- maximum visibility for your research: over $100 \mathrm{M}$ website views per year

At BMC, research is always in progress.

Learn more biomedcentral.com/submissions 